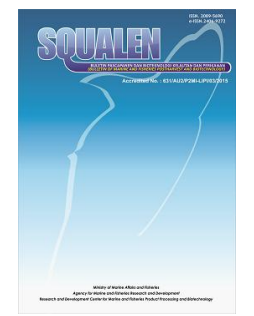

Squalen Bull. of Mar. \& Fish. Postharvest \& Biotech. 10 (1) 2015, 1-7

www.bbp4b.litbang.kkp.go.id/squalen-bulletin

Squalen Bulletin of Marine \& Fisheries Postharvest \& Biotechnology

ISSN: 2089-5690

e-ISSN: $2406-9272$

\title{
MECHANICAL PROPERTIES AND BIODEGRADABILITY OF ACID-SOLUBLE CHITOSAN-STARCH BASED FILM
}

\author{
Novalia Rachmawati ${ }^{1 *}$, Radestya Triwibowo ${ }^{1}$ and Roni Widianto ${ }^{2}$ \\ ${ }^{1}$ Indonesia Research Center for Marine and Fisheries Product Processing and Biotechnology, \\ JI. Ks. Tubun Petamburan VI Slipi Jakarta Pusat 10260, Indonesia. \\ ${ }^{2}$ Faculty of Fisheries and Marine Science, Diponegoro University. \\ Article history: \\ Received: 17 January 2015; Revised: 26 March 2015; Accepted: 7 April 2015
}

\begin{abstract}
Chitosan-starch blend film showed desirable elongation and oxygen transmission rate (OTR) values and demonstrated rapid degradation in soil burial treatment. The incorporation of higher glycerol concentration lowered tensile strength but increased the amount of transmittable water vapour. The biodegradability of chitosan-starch based film was tested using soil burial test. Chitosan-starch blend films were able to degrade naturally at slightly similar period, ranging from 72-87 days. The addition of glycerol was likely contributed to the high Water Vapour Transmission Rate (WVTR) value which faster the biodegradability of the film in soil. Among different type of acid solutions, lactic acid is less preferable solution to dissolve chitosan as it produced film with poor mechanical properties compared to acetic and formic acid. Based on its mechanical limitation, the film can be used as a coating based film for certain type of fish product, especially product with high lipid content.
\end{abstract}

Keywords: biodegradability, mechanical properties, oxygen transmission rate, water vapour transmission rate

\section{Introduction}

Food packaging is intended to protect food from its surrounding environment as well as preserve the nutritional value of food. Up to now, the packaging materials are still dominated by non-degradable fossil fuels based ingredients. Food in particular has short shelf life, thus the used of non-degradable food packaging for short term packaging arises as serious environmental problem (Soulestin et al., 2011). Biobased materials which in principle act similarly as regular packaging but degradable have been widely explored, including edible and biodegradable film from renewable sources. However, it has poor both mechanical and water barrier properties, therefore the industrial applications of this material are still limited (Soulestin et al., 2011).

Polysaccharides such as starch and cellulose, alone or in combination with other biopolymers, have been studied as potential renewable biopolymer for the manufacture of materials, adhesive, coating or glazing agents and emulsifier (Bourtoom, 2008). Starch usually contains $20-30 \%$ of amylose and 70 -
$80 \%$ amylopectine (Shit \& Shah, 2014). Amylose contributes to the film forming ability of starch and produces films that are flexible, odourless, tasteless, colourless, non-toxic, oxygen impermeable, and water soluble.

Chitosan is a natural polysaccharide formed by $\mathrm{N}$-deacetylation of chitin which produces repeating units of $\beta$-(1-4)-linked D-glucosamine (deacetylated unit) and $\mathrm{N}$-acetyl-D-glucosamine (acetylated unit) it has been widely used as food packaging due to its non-toxic and biodegradability properties (Caner et al., 1998; Fouad, 2008; Carneiro-Da-Cunha et al., 2010; Dean et al., 2013; ). Commercial chitosan has different characteristics such as grades of purity, chain lengths, charge densities and charge distributions, saltforms, viscosities and water retention values, molecular weights and molecular weight distributions, and degrees of deacetylation (Dean et al., 2013). The last two characteristics determine the mechanical and physical properties of chitosan-based film.

In the production of film from natural polymer, there are two methods available i.e. solvent casting and

*Corresponding author.

E-mail: novalia@kkp.go.id 
melt processing method (Dean et al., 2013). The first method is the only method available to produce chitosan film since chitosan has very low thermal stability and will be degraded before melting. While melt processing method consists of extrusion and kneading under thermal condition and involves plasticizer in the processing.

As hydrocolloid, chitosan has an interesting oxygen barrier property, when compared to lipids and polysaccharides based polymer, therefore it is interesting to further investigate this particular property. In addition, starch produces film with high flexibility while plasticizer addition play important role in the improvement of mechanical and structural properties of the film. This study aimed to incorporate chitosan from crab's shells with commercial starch and plasticizer to produce film which suitable for fishery product packaging with good mechanical and physical properties and easy to degrade in the environment. This paper elaborated mechanical and biodegradability characteristics of chitosan film and correlated it with potential application of the film as fish products' packaging.

\section{Material and Methods}

\subsection{Chitosan Preparation}

Commercial chitosan (1\% w/v) with $95.45 \%$ of degree of deacetylation was prepared by diluting $1 \mathrm{gr}$ of chitosan powder in $100 \mathrm{ml}$ of acid solutions $1 \%$ $(\mathrm{v} / \mathrm{v})$. Acids used were acetic acid, formic acid and lactate acid and provided by Sigma-Aldrich Singapore. Starch (non-graded) in distilled water was added into chitosan solution with ration $1: 1(\mathrm{v} / \mathrm{v})$ and properly mixed. Once the solid components dissolved completely, glycerol (Sigma) was added as plasticizer. The concentrations of glycerol used were $30 \%$ and $50 \%$ of total solid weight used in the solutions. The solutions were stirred at $50^{\circ} \mathrm{C}$ for 60 minutes.

Aliquot $300 \mathrm{~mL}$ of each chitosan solution was poured on square plate $(30 \times 11 \mathrm{~cm})$ made from Teflon $\circledast$ and dried in an oven at $40^{\circ} \mathrm{C}$ for $24 \mathrm{~h}$ then cooled at ambient temperature $\left( \pm 25^{\circ} \mathrm{C}\right)$ for $15 \mathrm{~min}$. Chitosan films were gently removed from plates and stored at dry conditions.

\subsection{Mechanical Test}

Mechanical attributes of chitosan, including tensile strength, elongation, and thickness, were measured in the Center for Chemical and Packaging (Balai Besar Kimia dan Kemasan), Ministry of Industry in Jakarta. The measurement was conducted based on American
Society for Testing and Material (ASTM) standard method. Tensile strength (MPa) and elongation (\%) were measured using the Universal Testing Machine. The testing properties were tested according to ASTM D882 for testing the tensile properties of thin plastic sheeting (ASTM International, 2012) and ASTM D.646/ D.646 $\mathrm{M}$ for thickness $(\mathrm{mm})$ (ASTM International, 2013). Water Vapour Transmission Rate (WVTR) and Oxygen Transmission Rate (OTR) were measured in the Packaging Laboratory, Research and Development Centre for Marine and Fisheries Product Processing and Biotechnology (RDCMFPPB). WVTR ( $\left.\mathrm{g} / \mathrm{m}^{2} / 24 \mathrm{~h}\right)$ and OTR $\left(\mathrm{ml} / \mathrm{m}^{2} / 24 \mathrm{~h}\right)$ were measured using PERME $®$ W3/031 and OX2/231 from Labthink, China, respectively, according to the manufacture's instruction.

\subsection{Biodegradability Test}

Biodegradation of chitosan film was evaluated by soil burial test. The film $\left(10 \mathrm{~cm}^{2}\right.$ each) were buried at $10 \mathrm{~cm}$ depth in polybags $(\mathrm{d}=15 \mathrm{~cm})$ containing soil (humus). A commercial HDPE film was used as control. Polybags were kept at room temperature $\left(25^{\circ} \mathrm{C}\right)$ and the moisture was maintained at $50-60 \%$. Films were visually observed and weighted every week for 6 week burial time. At the final day, the remaining films were cleaned and the morphology was observed under Scanning Electron Microscope (SEM) in the Physical Laboratory, RDCMFPPB.

Degradation equation was obtained by plotting the observed weight of film during soil burial treatment ( $x$ axis, linear) against the corresponding time of observation ( $y$-axis, linear). Linear regression obtained from the data was applied for the curve fitting. Assuming that the film reaches zero weight when fully decomposed, the time needed by each film to be fully degraded can be estimated.

\section{Results and Discussion}

\subsection{Mechanical Properties}

As natural polysaccharide, starch has been widely used as raw material of polymer. Several modifications have been proposed to increase the physical and mechanical properties of starch based film, such as blending with other natural polymer including chitosan which produces cheap, non-toxic and environmentally friendly film. Hydrogen bonds between amino group of chitosan and hydroxyl (poly aldehyde) groups of starch generate film with good mechanical properties (Rinaudo, 2006; Wittaya, 2012). In this study, the ratio between starch and chitosan was 1:1. Properties of blended films were presented in Figure 1. 


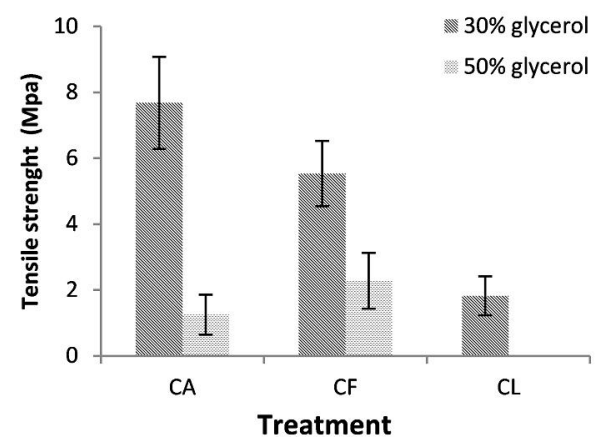

(a)

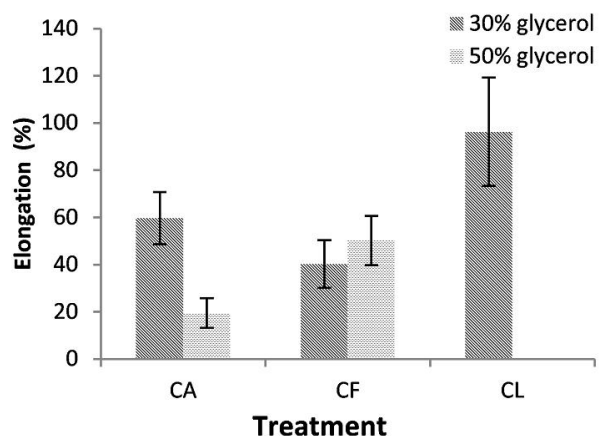

(b)

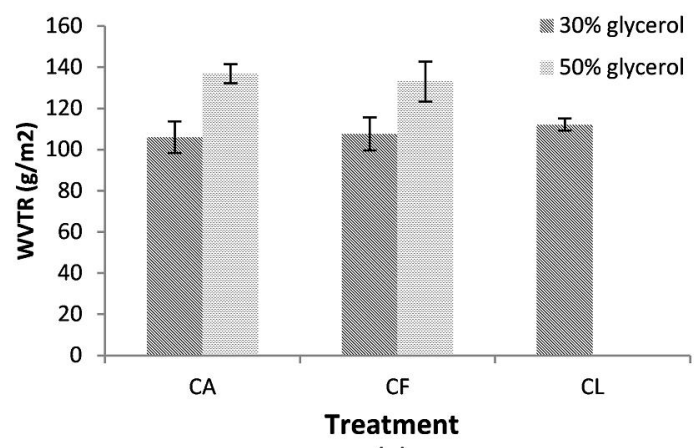

(c)

Figure 1. Tensile strength (a), elongation (b) and WVTR (c) of chitosan-starch based film blended in acetic acid (CA), formic acid (CF) and lactic acid (CL).

Acid types and plasticizer concentration markedly affected tensile strength. Acetic acid gave the highest tensile strength followed by formic and lactic acid, while the addition of plasticizer markedly reduced the tensile strength. These results were in accordance with a study of Caner et al. (1998) where chitosan diluted in acetic acid had slightly higher tensile strength than those diluted in formic and lactic acid. Furthermore, their result showed that $50 \%$ of plasticizer produced film with lower tensile strength ( $16.95 \mathrm{MPa}$ ) compared to $25 \%$ of plasticizer (22.99 MPa). The addition of plasticizer, such as glycerine, into polymer triggers the breakdown of polymer-polymer interaction yields a more porous, flexible and less cohesive structure (Liew et al., 2014). Bourtoom (2008) described the involvement of plasticizer agent to reduce brittleness of polymer packaging by disrupting the hydrogen bonds between polymer chains. The molecules of glycerol are relatively small thus easy to distribute in between the polymer bonds and effectively break the chain apart.

Although the tensile strength values observed from this study were lower than the required values for chitosan as food polymer packaging (Shit \& Shah, 2014), all films produced desirable elongation values $(20-80 \%)$ with lactic acid chitosan as the highest (96.26\%). A good film should have high flexibility and high elongation at break to avoid damage from any tension (Liew et al., 2014). Lactic acid produced film with low tensile strength but very high elongation. Caner et al. (1998) reported similar result where the percentage of elongation of polymer film was inversely correlated with tensile strength. However, based on the tensile strength values, films produced in this study have not yet met the suitable requirement for food packaging.

In this study, WVTR was independent on acid types but dependent on the amount of plasticizer. The higher concentration of plasticizer increased the amount of transmittable water vapour (Figure 1c). The higher amount of hydrophilic sites from plasticizer leads to the increasing film's flexibility thus reduces its water vapour resistance (Shit \& Shah, 2014). According to Karbowiak et al. (2006), the properties of hydrocolloid film depends on the relative humidity and temperature hence cross linking between hydrocolloid and hydrophilic plasticizer increases the water sorption. Although paired $t$ test does not give any significant different between acid treatments, however data in this study showed that acetic acid produced chitosan film with the lowest WVTR followed by formic and lactic acid, which in agreement with a study done by Caner et al. (1998).

The physical property of film which did not affected by acid and plasticizer treatments was thickness which ranges from $0.08-0.1 \mathrm{~mm}$ (Table 1). Furthermore, OTR 
Table 1. Thickness and OTR of blended chitosan film

\begin{tabular}{ccc}
\hline Treatment & Thickness $(\mathbf{m m})$ & OTR $(\mathrm{ml} / \mathrm{m} 2 / \mathbf{h})$ \\
\hline CA 30 & 0.08 & 1.44 \\
CA 50 & 0.1 & 1.44 \\
CF 30 & 0.08 & 1.44 \\
CF 50 & 0.08 & 1.44 \\
CL 30 & 0.07 & 1.44 \\
\hline
\end{tabular}

was also independent from acid and plasticizer treatments. OTR values for all treatment were 1.44 $\mathrm{ml} / \mathrm{m}^{2} / \mathrm{h}$. These findings confirmed that hydrocolloid films do not have good barrier properties against water vapour but they strongly block the oxygen transmission (Shit \& Shah, 2014). Good oxygen barrier property of chitosan is might be due to the strong interactions of functional groups which hamper the movement of polymer chain (Jeon et al., 2002).

\subsection{Biodegradability Test}

Soil burial was performed to evaluate the biodegradability of the biopolymer. The soil temperature was maintained at $\pm 25^{\circ} \mathrm{C}$ with $50-60 \%$ humidity. The percentage weight loss of film during soil burial treatment was presented in Figure 2. All films degraded at more than $60 \%$ of their initial weight, except for the commercial HDPE plastic (control) which remained at the same weight until the end of experiment. Chitosan in lactic acid was totally degraded at week 6 (100\% of weight loss). Lactic acid is one of food acids with mild acidic taste and classified as Generally Recognized As Safe (GRAS) (Narayanan et al., 2004). Its polymers are biodegradable and due to the biochemical properties, they have various medical applications such as orthopaedic implants and drug delivery mean. However, development of lactic acid polymer, Poly Lactic Acid (PLA) produces film which is stable under normal condition but rapidly degraded at high temperature, high moisture and high microbial activity (National Research Council, 2001). The degradation of this polymer consists of two continues steps starting with hydrolysis, which is marked by brittleness, and followed by bacterial degradation which produces $\mathrm{CO}_{2}$, water and humus.

Based on the linier correlation between weight lost data and burial period (Figure 3), the predicted time for each chitosan film to be fully degraded were presented in Table 2. All treatment, except chitosan in lactic acid solution, have almost similar period to be fully degraded. However, higher concentration of

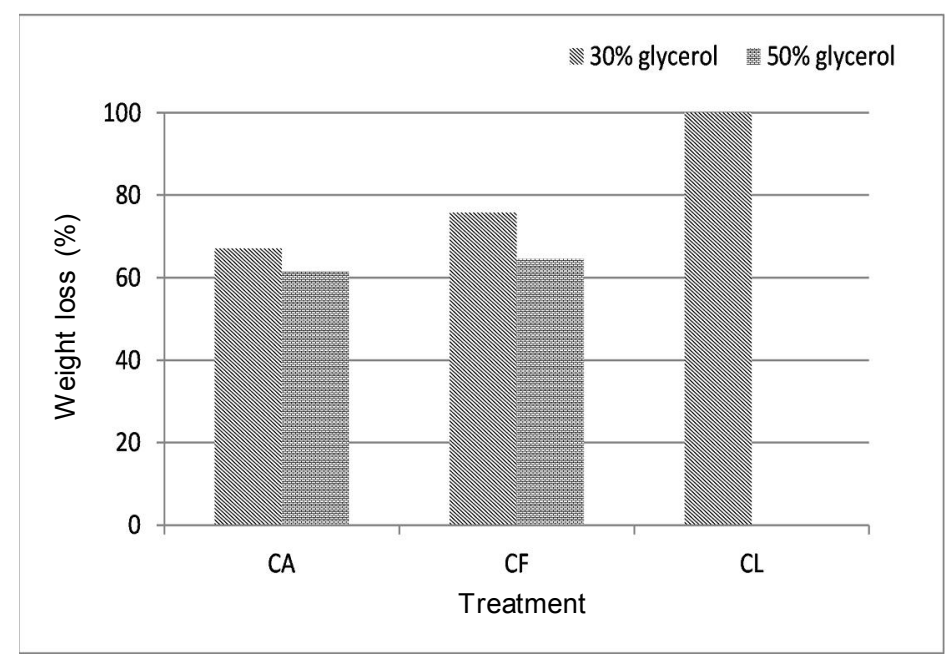

Figure 2. Percentage of weight loss of chitosan at the end of soil burial treatment in acetic acid (CA), formic acid (CF) and lactic acid (CL). 


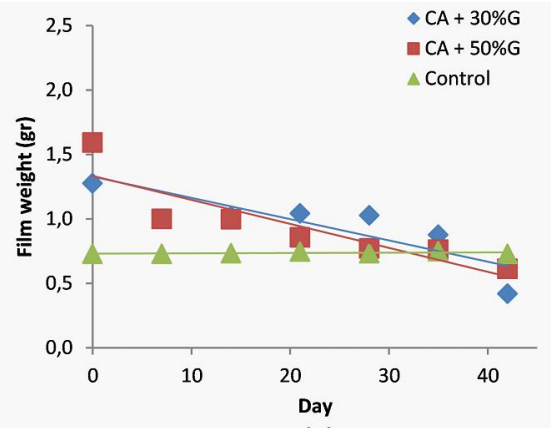

(a)

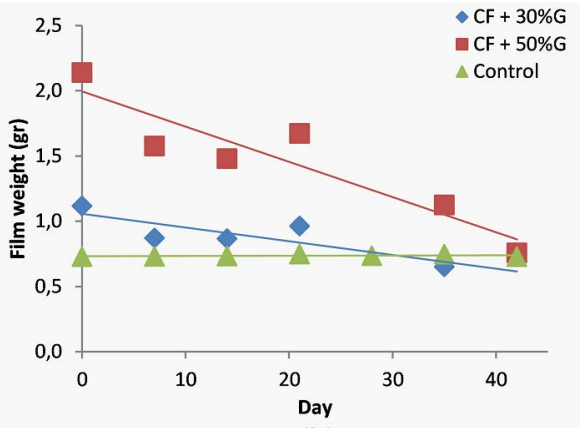

(b)

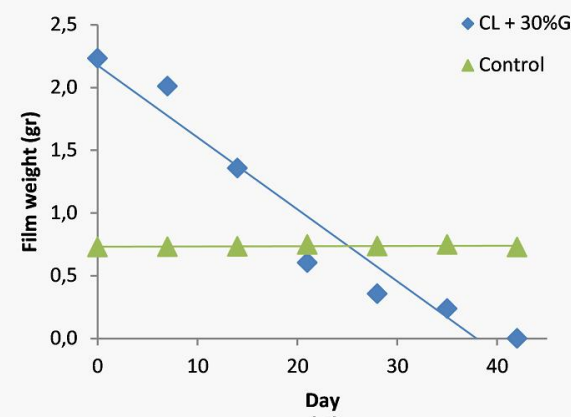

(c)

Figure 3. Linier regression of weight lost during burial treatment of chitosan-starch based film blended in (a) acetic acid, (b) formic acid and (c) lactic acid compared with control (HDPE).

Table 2. Predicted degradation time of chitosan film

\begin{tabular}{ccc}
\hline Chitosan formula & $\mathbf{R}^{\mathbf{2}}$ & Degradation time (days) \\
\hline CA $+30 \%$ gly & 0.75 & 81 \\
CA $+50 \%$ gly & 0.78 & 72 \\
CF $+30 \%$ gly & 0.68 & 101 \\
CF $+50 \%$ gly & 0.85 & 74 \\
CL $+30 \%$ gly & 0.94 & 38 \\
Control (commercial HDPE) & 0.11 & 3662 \\
\hline
\end{tabular}

plasticizer shortened the biodegradability period from 81 to 72 days and 101 to 74 days for films diluted in acetic acid and formic acid, respectively. As has been shown previously, plasticizer contributed to the increasing WVTR value of the film and produced more hydrophilic film therefore it was easily degraded by soil microorganisms. A study done by Dean et al. (2013) showed similar results where film made of chitosan and glycerol at ratio 75:25 (w/w) was biodegraded faster than those made from $90: 10(\mathrm{w} / \mathrm{w})$ of chitosan and glycerol. This can be explained as glycerol increases the water content of material through sorption/desorption mechanisms which tends to uptake water molecules from the environment into the film.

Visualization of chitosan film was performed under Scanning Electron Microscope (Figure 4). Samples were taken as representative from different treatment to compare the film morphology before and after soil burial, except for chitosan in lactic acid which has been totally degraded before the end of experimental period. Prior to soil burial, chitosan films have smooth appearance which completely changed after 6 weeks of burial. Debris was observed at the end of burial 

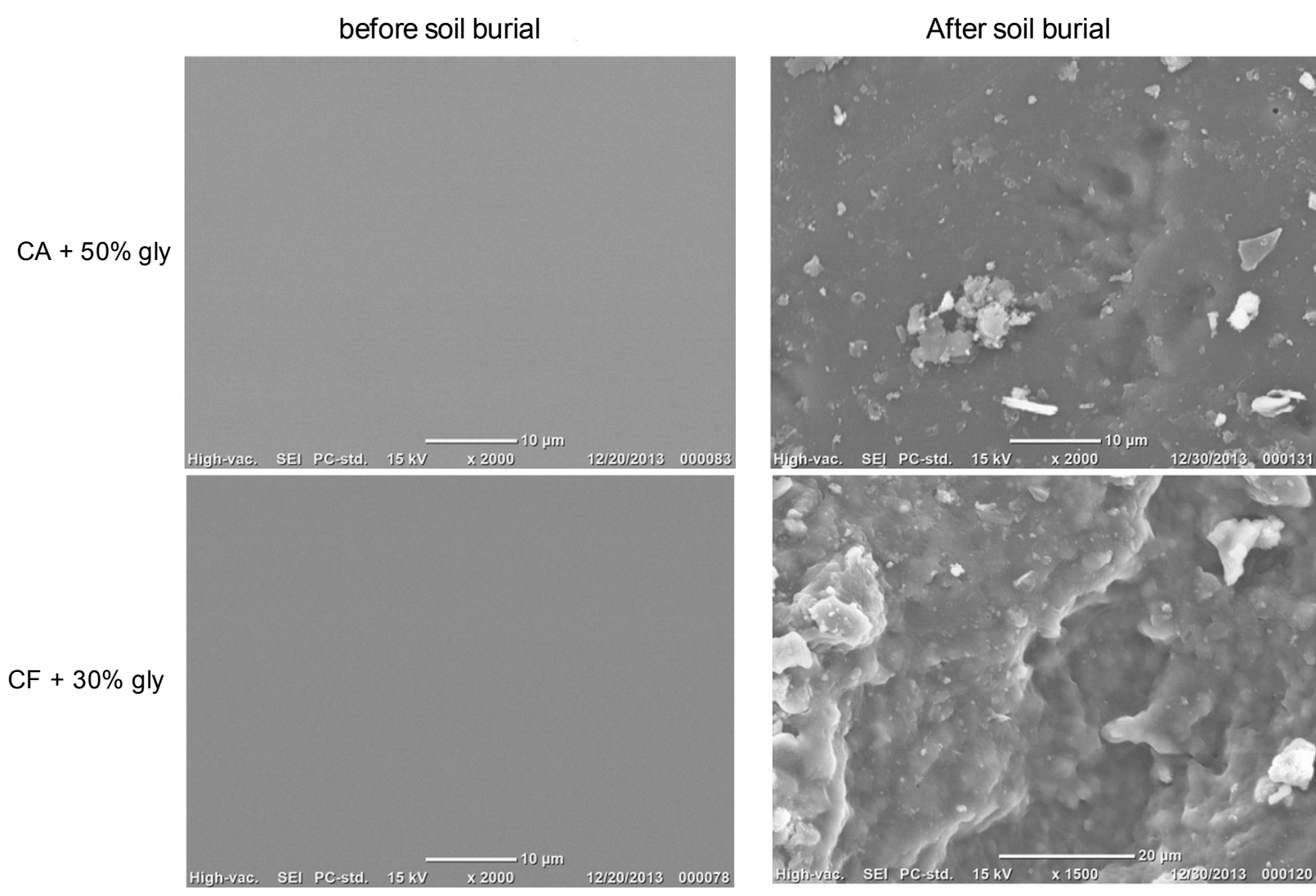

Figure 4. Visualization of chitosan-starch based film before and after soil burial treatment.

period which probably due to mixed particles from soil media which cannot be eliminated from the film's surface.

Based on its mechanical and physical characteristics, chitosan film from this study has limitation to be applied as packaging in a wide range of product. The high water transmission rate causes the film less suitable packaging for fish with high water content. However the low oxygen transmission rate provides more favourable condition to prevent oxidation, therefore it is more suitable to be used as film coating for cooked fish with high lipid content. The ability of chitosan coating to prevent oxidation has also been observed in refrigerated herring and Atlantic cod (Jeon et al., 2002), rainbow trout (Ojagh et al., 2010) and pink salmon (Sathivel, 2005). Chitosan film also has potency to be used as coating agent for different type of sausages, including fish sausage (Adzaly, 2014), meat sausage (Hromis et al., 2013, Krkiæ et al., 2013) and pork sausage (Siripatrawan \& Harte, 2010).

\section{Conclusion}

The physical and mechanical properties of natural polymer or film made from chitosan and starch blend was improved by the addition of glycerol as plasticizer The highest tensile strength was only $7.5 \mathrm{MPa}$ and observed from chitosan in acetic acid with $30 \%$ of glycerol, while the elongation values for all films were under desirable range (20-96.26\%). Although the physical properties limitation of the chitosan-starch blend reduces its application as the main packaging, the chitosan-starch based film nevertheless has potency to be used as a coating based film for certain type of fish product, such as fish product with high lipid content. On the other hand, higher concentration of plasticizer shortened the biodegradability period of the film, from 81 to 72 days and 101 to 74 days for films diluted in acetic acid and formic acid, respectively. Therefore, the biodegradability of the film in nature enhances more advanced development or studies of natural biopolymer as alternative source of food packaging to reduce the usage of fossil fuel-based polymers.

\section{References}

Adzaly, N. Z. (2014). Development of a novel sausage casing made of chitosan and its performance under traditional sausage manufacturing conditions. Theses. Michigan State University, Ann Arbor. 
ASTM International. (2012). Standard Test Method for Tensile Properties of Thin Plastic Sheeting (Vol. ASTM D882 - 12). West Conshohocken, Pennsylvania: ASTM International.

ASTM International. (2013). Standard Test Method for Mass Per Unit Area of Paper and Paperboard of Aramid Papers (Basis Weight) (Vol. ASTM D646-13). West Conshohocken, Pennsylvania: ASTM International.

Bourtoom, T. (2008). Plasticizer effect on the properties of biodegradable blend film from rice starch-chitosan. Songklanakarin Journal of Science \& Technology, 80, 149.

Caner, C., Vergano, P. J., \& Wiles, J. L. (1998). Chitosan Film Mechanical and Permeation Properties as Affected by Acid, Plasticizer, and Storage. Journal of Food Science, 63(6), 1049-1053. doi: 10.1111/j.13652621.1998.tb15852.x

Carneiro-Da-Cunha, M. G., Cerqueira, M. A., Souza, B. W. S., Carvalhoc, S., Quintas, M. A. C., Teixeira, J. A., \& Vicente, A. A. (2010). Physical and thermal properties of a chitosan/alginate nanolayered PET film. Carbohydrate Polymers, 82(1), 153-159. doi: 10.1016/j.carbpol.2010.04.043

Dean, K., Sangwan, P., Way, C., Zhang, X. Q., Martino, V. P., Xie, F. W., \& Averous, L. (2013). Glycerol plasticised chitosan: A study of biodegradation via carbon dioxide evolution and nuclear magnetic resonance. Polymer Degradation and Stability, 98(6), 1236-1246. doi: 10.1016/j.polymdegradstab.2013.03.004

Fouad, D. R. G. (2008). Chitosan as an antimicrobial compound. Modes of action and resistance mechanisms. (PhD), Bonn University, Bonn, Germany.

Jeon, Y. J., Kamil, J., \& Shahidi, F. (2002). Chitosan as an edible invisible film for quality preservation of herring and Atlantic cod. Journal of Agricultural and Food Chemistry, 50(18), 5167-5178. doi: 10.1021/ jf011693।

Karbowiak, T., Hervet, H., Leger, L., Champion, D., Debeaufort, F., \& Voilley, A. (2006). Effect of plasticizers (water and glycerol) on the diffusion of a small molecule in iota-carrageenan biopolymer films for edible coating application. Biomacromolecules, 7(6), 2011-2019. doi: 10.1021/bm060179r

Krkiæ, N., Šojiæ, B., Laziæ, V., Petroviæ, L., Mandiæ, A., Sedej, I., \& Tomoviæ, V. (2013). Lipid oxidative changes in chitosan-oregano coated traditional dry fermented sausage Petrovská klobása. Meat Science, 93(3), 767-770. doi: http://dx.doi.org/ 10.1016/j.meatsci.2012.11.043
Hromis, N. M., Sojic, B. V., Skaljac, S. B., Lazic, V. L., Dzinic, N. R., Suput, D. Z., \& Popovic, S. Z. (2013). Effect of chitosan-caraway coating on color stability and lipid oxidation of traditional dry fermented sausage. Acta Periodica Technologica, 44, 57-65.

Liew, K. B., Tan, Y. T. F., \& Peh, K. K. (2014). Effect of polymer, plasticizer and filler on orally disintegrating film. Drug Development and Industrial Pharmacy, 40(1), 110-119. doi: 10.3109/03639045.2012.749889

Narayanan, N., Roychoudhury, P. K., \& Srivastava, A. (2004). L (+)lactic acid fermentation and its product polymerization. Electronic Journal of Biotechnology, 7(2), 167-179.

National Research Council. (2001). Carbon management implications for $R \& D$ in the chemical sciences and technology. Workshop report to the Chemical Sciences Roundtable (D. o. E. a. L. Studies, Trans.). Washington, D.C. National Academy Press.

Ojagh, S. M., Rezaei, M., Razavi, S. H., \& Hosseini, S. M. H. (2010). Effect of chitosan coatings enriched with cinnamon oil on the quality of refrigerated rainbow trout. Food Chemistry, 120(1), 193-198. doi: http:// dx.doi.org/10.1016/j.foodchem.2009.10.006

Rinaudo, M. (2006). Chitin and chitosan: Properties and applications. Progress in Polymer Science, 31(7), 603-632. doi: http://dx.doi.org/10.1016/ j.progpolymsci.2006.06.001

Sathivel, S. (2005). Chitosan and Protein Coatings Affect Yield, Moisture Loss, and Lipid Oxidation of Pink Salmon (Oncorhynchus gorbuscha) Fillets During Frozen Storage. Journal of Food Science, 70(8), 455459. doi: 10.1111/j.1365-2621.2005.tb11514.x

Shit, S. C., \& Shah, P. M. (2014). Edible Polymers: Challenges and Opportunities. Journal of Polymers, 2014, 1-13.

Siripatrawan, U., \& Harte, B. R. (2010). Physical properties and antioxidant activity of an active film from chitosan incorporated with green tea extract. Food Hydrocolloids, 24(8), 770-775. doi: 10.1016/ j.foodhyd.2010.04.003

Soulestin, J., Prashantha K., Lacrampe M.F., \& Krawczak P. (2011). Bioplastics Based Nanocomposites for Packaging Applications. In S. Pilla (Ed.), Handbook of Bioplastics and Biocomposites Engineering Applications (pp. 77-120). Canada: Scrivener Publishing LLC

Wittaya, T. (2012). Rice Starch-Based Biodegradable Films: Properties Enhancement. In A. A. Eissa (Ed.), Structure and Function of Food Engineering (pp. 103134): InTech 